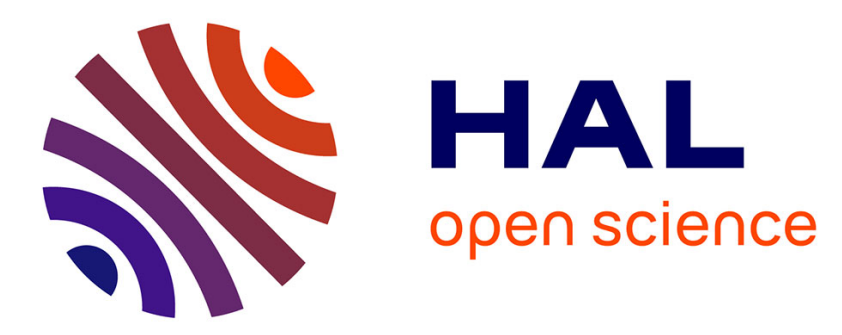

\title{
Influence of alkali and Si-based treatments on the physical and chemical characteristics of miscanthus stem fragments
}

Estefania Boix, Frédéric Georgi, Patrick Navard

\section{- To cite this version:}

Estefania Boix, Frédéric Georgi, Patrick Navard. Influence of alkali and Si-based treatments on the physical and chemical characteristics of miscanthus stem fragments. Industrial Crops and Products, 2016, 91, pp. 6-14. 10.1016/j.indcrop.2016.06.030 . hal-01354141

HAL Id: hal-01354141

https://hal-mines-paristech.archives-ouvertes.fr/hal-01354141

Submitted on 27 Apr 2017

HAL is a multi-disciplinary open access archive for the deposit and dissemination of scientific research documents, whether they are published or not. The documents may come from teaching and research institutions in France or abroad, or from public or private research centers.
L'archive ouverte pluridisciplinaire HAL, est destinée au dépôt et à la diffusion de documents scientifiques de niveau recherche, publiés ou non, émanant des établissements d'enseignement et de recherche français ou étrangers, des laboratoires publics ou privés. 


\title{
Influence of alkali and Si-based treatments on
}

\section{the physical and chemical characteristics of}

\section{miscanthus stem fragments}

Estefania Boix, Frederic Georgi and Patrick Navard*

MINES ParisTech, PSL Research University, CEMEF** - Centre de mise en forme des matériaux, CNRS UMR 7635, CS 10207 rue Claude Daunesse 06904 Sophia Antipolis Cedex, France

* To whom correspondence must be addressed (patrick.navard@mines-paristech.fr)

** Member of the European Polysaccharide Network of Excellence (www.epnoe.eu)

\begin{abstract}
Lignocellulosic materials in the form of miscanthus stem fragments were treated in order to limit their drawbacks (hydrophilicity, degradability, compatibility) when willing to use them as fillers for new bio-based concrete composites. This included a pre-alkaline soaking of the stem fragments followed by sol-gel tetraethoxysilane treatments in aqueous solutions. Since a modification of miscanthus using these methods has not been previously reported, the efficiency of the reactions was investigated at different $\mathrm{pH}$ conditions. The hydrolysis and condensation reactions of silane were monitored through the colorimetric silicomolybdenum method; the miscanthus structural changes, surface topography and the evidence of silica deposition on the fragments' surface was investigated by X-ray diffraction, X-ray photoelectron
\end{abstract}


spectroscopy, electron microscopy and infrared spectroscopy. Results showed that the highest hydrophobicity, calculated by the water absorption of the stem fragments, was obtained for silane treatments in acidic and basic media. However, silica condensation followed different kinetics for each media conditions and headed to different morphology of the miscanthus coating. The alkali pre-treatment led to more hydrophilic products but with a more fibrillated surface, which may be potentially useful for its application in concrete.

\section{Key-words}

Silane; Silica; Alkali; Miscanthus; Hydrophobisation 


\section{INTRODUCTION}

Composites made of a filler or a reinforcing agent embedded into a matrix have properties influenced by the properties of the individual components and by the interface between components. When dealing with lignocellulosic fillers mixed with cements or polymers, the hydrophilic/hydrophobic character of the lignocellulosic components can be a critical parameter for ensuring a proper compatibility with the matrix. When the matrix is based on cement, treatments like boiling water, alkali, silane, titanium alkoxide were tried (Vo and Navard, 2016). In most of the cases, the objective is to increase the hydrophobicity of the filler and improve the affinity between the inorganic matrix (cement) and the plant filler.

Treatment with alkalis is a major step in the treatment of biomass for producing cellulose as it can remove some lignins, hemicelluloses, pectins and other minor components like wax (Mwaikambo and Ansell, 2002; Sun et al., 2000). In addition to removing chemicals, and also due to the swelling induced by the treatment, the structure and mainly the surface of a lignocellulosic object is changed, being rougher. These leads to better mechanical interlocking due to the increase of the surface area and also the exposition of more hydroxyl groups, increasing the number of possible reactions. All these effects are increasing interface strength (Valadez-Gonzalez et al., 1999).

Aside having been obviously used as a coupling agent for glass fibres and silica particles in polymer matrices, silanes were extensively tested as a compatibilisation agent for natural fillers. For polymers, the reason is the possibility to create silanol moieties grafted onto the $\mathrm{O}-\mathrm{H}$ bonds, always present at the surface of a lignocellulosic material, in order to decrease its hydrophobicity and improve the compatibility with hydrophobic polymers as polyolefins. It is recognized that the chemical reactions 
leading to this improvement follow four steps, hydrolysis, self-condensation, then a stage of adsorption which can be followed by the formation of $\mathrm{Si}-\mathrm{O}-\mathrm{C}$ bonds under heating, leading to a grafting of silanol onto the natural stem surface (Bilba and Arsene, 2008; Xie et al., 2010). Such coverage of the filler surface reduces the number of hydroxyl groups, decreasing thus hydrophilicity. But it has also the advantage of forming a link between the filler (one end of silanol reacts with hydroxyl groups) and the matrix (the other end form a bond with a matrix functional group). Silane treatments were applied for bio-based concrete materials. Such treatment applied on bagasse fibres resulted in a decrease in water absorption by the fibres, an improvement in the affinity between the cement matrix and natural filler, and also shortened the setting time of the composite (Bilba and Arsene, 2008).

Sol-gel processes have been widely used for material synthesis, such as metalloid oxides or materials coating. In the case of $\mathrm{Si}$-species, alkoxysilanes $\left(\mathrm{Si}(\mathrm{OR})_{4}\right)$ are typically used as a precursor. The hydrolysis of alkoxysilanes is generally performed in a mixture of alcohol, water and an acid or base catalyst. The role of the alcohol is to favour the miscibility of the alkoxysilane with the aqueous media. However, the hydrolysis of these precursors at low concentration can also be performed in aqueous media, specially under acid or basic catalysis to produce silicic acid $\left(\mathrm{Si}(\mathrm{OH})_{4}\right)$, which subsequently form oligomers and other species with other monomeric silicic acid or silicates $\left(\mathrm{Si}(\mathrm{OR})_{\mathrm{x}} \mathrm{O}_{\mathrm{y}}^{-(4-\mathrm{x})}\right)$. The partial or total hydrolysis of the alkoxysilane precursor $\left(\mathrm{Si}(\mathrm{OR})_{4}\right)$ into $\left[\mathrm{Si}(\mathrm{OR})_{\mathrm{x}}(\mathrm{OH})_{\mathrm{y}}\right]$ is required for the further condensation of silica $\left(\mathrm{SiO}_{2}\right)$ (Iler, 1979) and/or the reaction between silanol groups ( $\mathrm{Si}-\mathrm{OH})$ and cellulose hydroxyl groups (Castellano et al., 2004). The subsequent condensation reaction has been shown to be faster at circumneutral pH (between pH 6 and 8) (Iler, 1979). Nonetheless, their 
response to silane treatments and the resulting materials properties in the presence of natural plants depends on the nature of the stem (Pehanich et al., 2004).

The main advantages of using miscanthus plants as a source of renewable materials are its environmental performances and its high yield. Moreover, from the point of view of materials application, the structure of miscanthus fragments provide thermal insulating properties, firmness and it is considered a strong plant when compared to other lignocellulosic materials such as straw (Pude et al., 2005). The presented work consists of an optimised processing of miscanthus plants based on alkoxysilane treatments under mild conditions. The investigation focuses on resolving three main incompatibilities when using miscanthus as materials filler: i) to reduce water absorption by the natural stems that may result in materials dimensional instability, ii) to provide the stem fragments with a coating acting as a protection against degradation by the material matrix such as polymer or cement and iii) to modify the plant surface in order to increase the affinity between the natural plant and the matrix.

The final objective of this work is to find ways to improve the manufacturing of miscanthus-based concrete by pre-treating the biomass. To this end, a first study, reported here, was performed where miscanthus stem fragments were treated with $\mathrm{Si}$ based compounds together with an alkali pre-treatment. The present article reports the details of this pre-treatment. The alkoxysilane used in this study for the miscanthus stem fragments treatment is tetraethoxysilane (TEOS). This silica precursor was selected due to the possibility to be hydrolysed completely into silicic acid, which allows monitoring the hydrolysis and condensation reactions through the silicomolybdenum method (Belton et al., 2012). Besides, the absence of alkyl groups gives a lower hydrophobic character to the molecule and therefore aqueous media of low concentrations of TEOS 
can be used for its hydrolysis without needing an organic solvent such as ethanol (Bilba and Arsene, 2008).

\section{EXPERIMENTAL SECTION}

\subsection{Materials}

Miscanthus X giganteus stems were harvested from Seine-et-Marne region (France) on March 2014 by the BES group (Biomass Environment System) and grinded by SD Tech SA (Alès, France). The resulting miscanthus objects received are thus stem fragments. Tetraethoxysilane (TEOS, $99.99 \%)$, ammonia solution $\left(\mathrm{NH}_{3}, 28-30 \%\right)$, potassium

sulphate $\left(\mathrm{K}_{2} \mathrm{SO}_{4}, \geq 99 \%\right)$ sodium acetate $\left(\mathrm{CH}_{3} \mathrm{COONa}, \geq 99 \%\right)$ and Aquanal ${ }^{\mathrm{TM}}$-plus silicon/silicium ( $\mathrm{Si}$ ) $0.01-0.25 \mathrm{mg} / \mathrm{L} \mathrm{Si}^{4+}$ (vis) test kit were purchased from SigmaAldrich. Sodium hydroxide pellets $(\mathrm{NaOH}, \geq 97 \%)$ were purchased from Merck and glacial acetic acid $\left(\mathrm{CH}_{3} \mathrm{CO}_{2} \mathrm{H}, 99.83 \%\right)$ was purchased from Fisher Scientific. All experiments were performed with distilled water.

\subsection{Alkali pre-treatment}

Alkali treatment of the stems was applied to some untreated, as received miscanthus stem fragments. Alkali treatment was conducted by submerging untreated stem fragments in a $5 \%$ sodium hydroxide solution during 30 minutes under stirring. Afterwards, stems were filtered and rinsed with acidified water (1\% acetic acid glacial) followed by abundant water until rinsing water had a neutral $\mathrm{pH}$ and a conductivity lower than $50 \mu \mathrm{S} / \mathrm{cm}$. Samples were finally dried in oven (Salvis Lab Vacucenter, Switzerland) at $80{ }^{\circ} \mathrm{C}$ and vacuum. 


\subsection{Silane treatment of the stems}

The silane emulsion treatment was applied to both untreated and previously alkali treated miscanthus stem fragments by using a $2.6 \% \mathrm{v} / \mathrm{v}(115 \mathrm{mM})$ of silica precursor tetraethoxysilane ( TEOS) in aqueous media: a) water $(\mathrm{pH} \approx 6), \mathrm{b})$ acid $(\mathrm{pH} 4)$ or $\mathrm{c}$ ) basic ( $\mathrm{pH} 10)$. The acidic media was a $\mathrm{pH} 4$ buffer prepared with a mixture of $0.1 \mathrm{M}$ glacial acetic acid and $0.1 \mathrm{M}$ sodium acetate. The basic media consisted of a $0.06 \mathrm{M}$ ammonia solution. TEOS aliquot was added into the aqueous solution and five minutes later, stem fragments were submerged and kept under stirring for two hours.

Alternatively, other stem fragments were also stirred in distilled water for two hours to prepare the untreated miscanthus sample aiming a better comparison to treated samples. The experimental setting consisted of $6 \mathrm{~g}$ of stem fragments added into $81.6 \mathrm{ml}$ solution. The amount of miscanthus was chosen after preliminary tests in which increasing amounts of stem fragments were submerged in water in a $100 \mathrm{ml}$ volumetric flask and stirred. The selected ratio stem mass/ solution volume was the highest allowing a homogeneous stirring of the mix. Following the water soaking or silane treatment; samples were filtered in a round mesh sieve, air dried for four hours and further dried in oven at $80{ }^{\circ} \mathrm{C}$ and under vacuum to allow condensation of silanol groups (Si-OH) without degrading the stem fragments. Once dried, stem fragments were rinsed with water several times to remove unreacted species or salts and dried again at $80{ }^{\circ} \mathrm{C}$ under vacuum.

The hydrolysis/condensation of the silica precursor was monitored using the Aquanal TM test kit. Aliquots of $0.2 \mathrm{ml}$ were extracted from the treatment solution at 20, 45, 70, 100 and 120 minutes and diluted as required to reach a concentration within the detection range of the analytical silicomolybdenum kit. 


\subsection{Optical microscopy}

The size distribution of grinded miscanthus stem fragments was determined using optical microscopy (Leica DM4500 P, Leica microsystems GmbH, Germany) operating in transmission mode and coupled with an image analysis software Archimed 4.2 (Microvision Instruments, France). The length and width of the fragments were measured using Image $\mathbf{J}$ software. The weighted arithmetic average and corresponding standard deviations of the fragment diameter, length and aspect ratio were calculated from the measurement of 350 fragments.

\subsection{Water and moisture absorption analysis}

The amount of water absorbed by the fragments was calculated based on, but not followed strictly, the standard method ASTM D 2402-01. For this experiment, a $5 \mathrm{ml}$ test tube was pierced with a heated needle multiple times to allow water to be extracted during centrifugation. This tube was then attached through the cap to a $50 \mathrm{ml}$ centrifuge tube cap using a metal wire. A quantity of stem fragments of $0.105 \pm 0.003 \mathrm{~g}$ was deposited in the small test tube and soaked by distilled water for 5 minutes before imposing a centrifugation during $10 \mathrm{~min}$ at $3000 \mathrm{rpm}$ (Universal 320R Andreas Hettich GmbH \& Co; Tuttlingen, Germany). Higher speeds of centrifugation were not applicable since it led to the separation of the two tubes. After centrifugation, samples were transferred to a metallic sample holder, weighted (wet weight, $W t_{w}$ ), oven dried 24 hours at $80{ }^{\circ} \mathrm{C}$ under vacuum and weighted again (dry weight, $W t_{d}$ ). This measurement was performed three times for each specimen. The weight percentage of water retention in respect to the dry weight of the stems was $100\left(W t_{w}-W t_{d}\right) / W t_{d}$.

Moisture absorption was measured for comparative purposes. In this case, stem fragments $(0.246 \pm 0.07 \mathrm{~g})$ were deposited in a metallic tray and kept in a closed recipient that contained saturated potassium sulphate and a thermometer/hygrometer 
device. Samples were kept in the recipient until no weight change, giving the wet weight, $W t_{w}$. The average conditions inside the closed chamber were measured as $25.2 \pm$ $0.6{ }^{\circ} \mathrm{C}$ and relative humidity of $94 \pm 1 \%$. All miscanthus stem samples were incubated in the same recipient at a time. Thereafter, samples were dried in oven at $80{ }^{\circ} \mathrm{C}$ under vacuum during 24 hours (dry weight, $W t_{d}$ ). The percentage of absorbed moisture was calculated using the same formula as for water absorption.

\subsection{Ash content analysis}

Approximately $1 \mathrm{~g}$ of miscanthus $\left(W t_{i}\right)$, previously dried at $105^{\circ} \mathrm{C}$ to ensure water elimination; was calcined inside ceramic crucibles in a muffle furnace (Nabertherm model LV15/11/B180, Lilienthal, Germany $30-3000{ }^{\circ} \mathrm{C}$ ), heating at a rate of $15^{\circ} \mathrm{C} / \mathrm{min}$ from $25^{\circ} \mathrm{C}$ until $600{ }^{\circ} \mathrm{C}$, kept at this temperature for 15 minutes and cooled down to room temperature. The remaining ashes were then weighted $\left(W t_{a}\right)$. The percentage of ash content was calculated from the difference in weight. Analysis was performed per triplicate and the $\%$ of ash content was calculated as $100\left(W t_{a} / W t_{i}\right)$.

\subsection{Fourier-Transform Infrared Spectroscopy analysis}

Attenuated Total Reflectance Fourier-Transform Infrared Spectroscopy (ATR-FTIR, Bruker Tensor 27) was used to analyse the surface of the treated stems (evidence of silica, chemical changes in the miscanthus fragments). All samples were previously freeze-dried in order to remove the water content. The instrument was operated from 4000 to $600 \mathrm{~cm}^{-1}$ with a $4 \mathrm{~cm}^{-1}$ resolution and 32 scans.

\subsection{Electron Microscopy (SEM/EDS)}

Scanning Electron Microscopy (SEM) was performed using a Philips FEI XL30, USA with $\mathrm{LaB}_{6}$ electron gun operated at $15 \mathrm{kV}$. Energy-dispersive X-ray spectroscopy 
(Bruker XFlash 6/60; Berlin, Germany) was used to analyse the composition of specific regions of the stem fragments.

\subsection{X-ray photoelectron spectroscopy (XPS)}

The X-ray photoelectron spectroscopic analyses of miscanthus stems were carried out by using a Thermo Scientific K-Alpha with an Al Ka monochromatic source (1484.68 eV) and equipped with a low energy flood-gun for charge compensation. Samples were attached to a holder with double-sized tape and placed in the XPS under vacuum $\left(10^{-9}\right.$ mBar). The area of analysis was an ellipsoid of $400 \mu \mathrm{m} \times 800 \mu \mathrm{m}$ and the sample depth analysis of $10 \mathrm{~nm}$. The preliminary survey was scanned at $1 \mathrm{eV}$ step and $200 \mathrm{eV}$ pass energy. For each element, 8 scans were taken with $0.1 \mathrm{eV}$ step and $40 \mathrm{eV}$ pass energy. The atomic composition was calculated with the Avantage ${ }^{\mathrm{TM}}$ software by integration of the element peak and with the following sensitivity factors: $1.000(\mathrm{C} 1 \mathrm{~s}), 1.800(\mathrm{~N} 1 \mathrm{~s})$, $2.930(\mathrm{O} 1 \mathrm{~s})$ and $0.817(\mathrm{Si} 2 \mathrm{p})$. The data presented for each element is the average of five analysed samples.

\subsection{XRD Diffraction}

Crystalline phases present in miscanthus stem fragments were identified using a Xpert Pro MPD diffractometer (Panalytical, Holland) X-ray diffractometer with a PixCel counter, $\mathrm{Cu}$ Ka source $(\lambda=0.154 \mathrm{~nm})$ with measured spectra ranged from $2 \theta$ angles between $5^{\circ}$ and $60^{\circ}$ with a scan rate of $0.1 \%$ and step acquisition time was $128 \mathrm{~s}$. The degree of crystallinity (\% Ic) of the analysed materials was calculated as follows:

This comparative method is based on the measurement of the intensity of the two main reflection peaks of cellulose at $2 \theta$ values of near $16^{\circ}\left(I_{a m}\right)$ and $22^{\circ}\left(I_{002}\right)$ corresponding to the amorphous and crystalline regions, respectively (Reddy et al., 2009). The average crystalline size was calculated applying the Scherrer equation (Scherrer, 1912) to the 
$002(\mathrm{hkl})$ lattice plane of miscanthus cellulose: $(\mathrm{D}(\mathrm{hkl})=\mathrm{K} \lambda / \mathrm{B}(\mathrm{hkl}) \cos \theta)$, were $(\mathrm{hkl})$ is the lattice plane, $\mathrm{D}$ is the size of the crystallite, $\mathrm{K}$ is the shape factor (assumed to be $0.84), \lambda$ is the XRD wavelength $1.54 \AA, \mathrm{B}(\mathrm{hkl})$ correspond to the full width half maximum of the peak and $2 \theta$ is the Bragg angle.

\section{RESULTS AND DISCUSSION}

\subsection{Macrostructure of miscanthus grinded stems}

When using natural stems as fillers for polymeric composites or concrete matrixes, both shape and size of the added particles are known to have an effect on the properties of the final composite. In natural fibres-concrete materials, long stems connect macrocracks whereas short stems are needed to bridge discreet microcracks. Furthermore, small stems uniformly distributed can increase the strength and ductility of the bio-concrete (Mehta and Monteiro, 2006). The aspect ratio of lignocellulosic fibres was also shown to determine the water absorptivity of a resulting polymeric composite (Thakur and Singha, 2010). The size of the fragments was requested to be within the range of what will be used in a following work to prepare concrete. The dimensional parameters of the received grinded miscanthus stem fragments were measured. The weighted arithmetic mean are $1.2 \pm 0.6 \mathrm{~mm}$ for the length (Fig. $1 \mathrm{a}), 0.2$ $\pm 0.1 \mathrm{~mm}$ for the width (Fig. $1 \mathrm{~b}$ ) and $6.6 \pm 4.4$ for the aspect ratio.

\subsection{TEOS hydrolysis and condensation}

Tetraethoxysilane was chosen as the silica precursor for miscanthus stem coating due to the possibility to monitor its hydrolysis/condensation with the colorimetric silicomolybdenum method, as it can be hydrolysed completely into silicic acid (Equation 1 a). The hydrolysis of TEOS (appearance of $\left.\mathrm{Si}(\mathrm{OH})_{4}\right)$ and its subsequent 
condensation (disappearance of $\mathrm{Si}(\mathrm{OH})_{4}$ ) was monitored using the silicomolybdenum blue method (Belton et al., 2012). In a first step, this reaction involves the formation of a yellow complex between molybdic acid and silicic acid (Equation $1 \mathrm{~b}$ ). As the molybdate can only allocate one monomeric silicic acid $\left(\mathrm{Si}(\mathrm{OH})_{4}\right)$ in its cage structure, silane molecules that are not totally hydrolysed into $\mathrm{Si}(\mathrm{OH})_{4}$ cannot be detected by this method. Dimeric silicic acid molecules are also detected as they are rapidly dissociated into monomers, but this does not apply for bigger oligomers. In a second step, the silicomolybdic yellow complex is transformed with a reducing agent into a silicomolybdenum blue complex of higher sensitivity as it has a greater molar extinction coefficient (Iler, 1979).

$$
\begin{gathered}
\left.\mathrm{Si}\left(\mathrm{OCH}_{2} \mathrm{CH}_{3}\right)_{4} \stackrel{\text { hydrolysis }}{\longrightarrow} \mathrm{Si(OH}\right)_{4} \\
7 \mathrm{Si}(\mathrm{OH})_{4}+12 \mathrm{H}_{6} \mathrm{Mo}_{7} \mathrm{O}_{24} \cdot 4 \mathrm{H}_{2} \mathrm{O}+174 \mathrm{H}_{2} \mathrm{O} \rightarrow 7 \mathrm{H}_{8} \mathrm{Si}\left(\mathrm{Mo}_{2} \mathrm{O}_{7}\right)_{6}+244 \mathrm{H}_{2} \mathrm{O}
\end{gathered}
$$

Equation 1. (a) Tetraethoxysilane hydrolysis into silicic acid and (b) complexation with molybdic acid to form the silicomolybdic complex .

The various treatments and the associated nomenclature is given on Table 1 . The complexation kinetics of available silicic acid (concentration of $\mathrm{Si}(\mathrm{OH})_{4}$ versus time) for the different reaction media are illustrated in Fig. 2. In an ideal case, completed hydrolysis of the added TEOS leads to a maximum of $115 \mathrm{mM}$ of monomeric $\mathrm{Si}(\mathrm{OH})_{4}$ available in solution. Nonetheless, this would require extreme acidic or basic conditions which would not favour the following condensation process for the formation of siloxane ( $\mathrm{Si}-\mathrm{O}-\mathrm{Si}$ ) bonds, which has a maximum yield at circumneutral $\mathrm{pH}$ (Iler, 1979). Therefore, one can assume that in our sol-gel systems, hydrolysis of TEOS and 
condensation of $\mathrm{Si}(\mathrm{OH})_{4}$ take place simultaneously. The control samples plotted in Fig. 2 show that the maximum levels of silicic acid are achieved in the acidic media, corresponding to ca $60 \mathrm{mM}$, whereas for basic and water media the levels of detected free $\mathrm{Si}(\mathrm{OH})_{4}$ are 36 and $27 \mathrm{mM}$, respectively. These values, much lower than the ideal total amount of silicic acid, are indicative of two hypothesis: condensation takes place in a similar kinetic frame as hydrolysis (suggested for the basic media) or hydrolysis has not been completed. The last hypothesis is the most probable for the water system, since the absence of a catalyst such as acid or base does not favour full hydrolysis of the alkoxysilane. Hydrolysis kinetics are predominant versus condensation in the water system, as observed by the positive slope of the $\mathrm{Si}(\mathrm{OH})_{4}$ concentration versus time (Fig. 2 a). However, the low slope is indicative of an expected slow hydrolysis. The addition of miscanthus decreases noticeably the final concentration of free silicic acid, which suggests that condensation is favoured in the presence of lignocellulose materials. W1 promotes condensation from the very beginning whereas the kinetics for alkali treated miscanthus, W2, are comparable to the blank (no miscanthus) in the first 40 minutes but clearly enhances condensation of Si-species after this point and reaches the same level as for W1. However, despite being alkali treated, the ash content analysis (Fig. 3) shows a slightly higher amount of non-calcined material for W2 than for W1. This suggests that the alkali treated miscanthus favours silica condensation on the plant surface and remains after washing, probably due to the higher amount of exposed hydroxyl groups after alkali treatment (Valadez-Gonzalez et al., 1999). Condensation in the acidic media (Fig. 2 b) is assumed to take place at a slow rate since hydrolysis is predominant in this solution; as observed by the positive slope of the silicomolybdenum kinetics. In this case, the presence of miscanthus also reduces the concentration of available monomer from the early stages. In contrast, condensation at basic pH (Fig. 2 c) takes place 
rapidly. The risk of synthesizing $\mathrm{SiO}_{2}$ in such highly alkali media is the re-dissolution of the mineral, which generally occurs over $\mathrm{pH} 10.5$ (Iler, 1979). Although since no increase in the silicic acid concentration slope was observed, we assumed that dissolution of precipitated silica did not take place. Availability of free monomeric silicic acid was also reduced when miscanthus was added, nevertheless the final concentration was the same with or without stem fragments. Therefore, it can be assumed that the lignocellulose material lead to a faster equilibrium between free $\mathrm{Si}(\mathrm{OH})_{4}$ and condensed $\mathrm{SiO}_{2}$.

\subsection{Physical properties of treated miscanthus}

Water absorption and ash content of miscanthus stem fragments were chosen as the two parameters to assess the efficiency of treatments. Water absorption as a parameter of hydrophilicity and ash content for measuring the amount of inorganic silica which has been deposited on the miscanthus stem surfaces. The results are given in Fig. 3. The untreated stem fragments absorbed around $80 \%$ of its dry weight in water. Such high water absorption and swelling of lignocellulosic materials is associated to the breakage of hydrogen bonding between cellulose, hemicellulose and lignin chains and the new hydrogen bonding formation between hydroxyl groups of the macromolecules and water (Mwaikambo and Ansell, 2002). The porosity of the material and the presence of non-crystalline components also contribute to the water absorption. As previously mentioned, alkali treatment of lignocellulosic materials with sodium hydroxide removes part of the lignin, pectin, waxy substances, natural oils, hemicelluloses and silica. This explains the brown colour of the resulting alkali solution, attributed to the chromophore groups generated from the reducing ends of hemicelluloses at basic $\mathrm{pH}$ (Sun et al., 2000). The final composition and structural changes depend on the temperature, $\mathrm{NaOH}$ 
concentration or duration of the treatment but also on the plant composition. Previously reported studies showed that $\mathrm{NaOH}$ treatment of miscanthus samples of different monolignol composition resulted in different percentages of extracted lignin and hemicelluloses (Li et al., 2014). In our work, the alkali treated miscanthus showed higher water absorption, due to the removal of hydrophobic components, due to more exposed $\mathrm{OH}$ groups from cellulose or hemicellulose on the stem surface and also due to an increase in the macroporosity of these stems as observed in Fig. $4 \mathrm{c}$ and 4 d. The water absorption data for silane treated samples evidences the hydrophobisation improvement by reducing the water intake, especially for A1 and B1. This result matches with the increase in the ash content, which can be associated to the amount of deposited silica as it is the only component added during treatment and not degraded at $600{ }^{\circ} \mathrm{C}$. The reduction of water intake by the silane treatment can be explained by two facts. Firstly and most probable, the precipitated silica acts as a barrier for water penetration into the plant and prevents water to react with lignocellulosic hydroxyl groups. Secondly, the silica deposition occupying the lignocellulosic macro pores could reduce the volume available to be filled by water molecules. However, the last suggestion can be discarded as the cross section analysis of silane treated stems (B2 as example in Fig. 4 d) did not evidence any precipitation of silica inside the plant pores, suggesting that deposition of the mineral took place only on the plant surface. For comparative reasons, the moisture absorption was also measured by keeping the miscanthus stem fragments during 9 days in a $94 \% \mathrm{RH}$ chamber at $25^{\circ} \mathrm{C}$. Results not reported here showed the same water absorption behaviour.

The amount of silanol groups $(\mathrm{Si}-\mathrm{OH})$ on the silica surface, which are responsible of the hydrophilic character of silica, is expected to differ according to the $\mathrm{pH}$ used during condensation. Considering that the silica isoelectric point is at $\mathrm{pH} 2$, (Iler, 1979) $\mathrm{A} 1 \mathrm{pH}$ 
$4)$ is expected to have slightly higher number of protonated forms $(\mathrm{Si}-\mathrm{OH})$ than $\mathrm{B} 1 \mathrm{pH}$ $10)$; as when $\mathrm{pH}$ increases, the amount of deprotonated silanol $\left(\mathrm{Si}^{-} \mathrm{O}^{-}\right)$slowly increases. However, no remarkable differences were observed in the water absorption values for A1 and B1, where both products had comparable amount of non-calcined content (silica). This could be a consequence of the post-silica heat treatment $\left(80{ }^{\circ} \mathrm{C}\right.$ and vacuum), promoting silanol condensation into siloxane or $\mathrm{Si}-\mathrm{O}-\mathrm{C}_{\text {cell }}$ through water elimination; and therefore, having a more similar chemical structure (Castellano et al., 2004).

\subsection{Morphological and structural characterisation of miscanthus stem fragments}

After two hours of the silane treatment, samples were dried in oven at $80^{\circ} \mathrm{C}$ under vacuum. Fig. 4 shows SEM micrographs of $(a, c)$ untreated and $(b, d)$ alkali treated samples, which evidence the morphological changes on the stem fragments surface. Untreated stems showed a more or less pronounced smooth surface which depended upon the type of tissues exposed. Fig. 4 a is showing a fragment with the outside surface of the stem visible. As soon as stem fragments are alkali treated (Fig. 4 b), all surfaces are more "rough" and more fibrillated due to the removal of some lignin, wax and hemicelluloses, as classically observed (Reddy et al., 2009; Valadez-Gonzalez et al., 1999). Among the different components in lignocellulosic materials, such as waxes, lignin, pectin or hemicelluloses, only cellulose has a crystalline structure. The X-ray diffraction analysis (Fig. 4, right) showed no difference between the diffraction peaks of untreated and alkali treated miscanthus, as can be inferred considering the low $\mathrm{NaOH}$ concentration ( $5 \% \mathrm{NaOH}$ solution treatment). At this concentration and at room temperature, cellulose is not dissolved nor mercerised, i.e. transformed irreversibly into 
a cellulose II-type of crystalline structure (Cuissinat and Navard, 2006). The degree of crystallinity was calculated as $44.5 \%$ for untreated miscanthus and $63.8 \%$ for the alkali treated counterpart. The higher crystallinity of the alkali treated plant is the result of the removal of non-crystalline compounds. Alkali treatment of Napier grass fibres also resulted in an increase of crystallinity (Reddy et al., 2009). The calculated crystallite size by the Scherrer equation showed that cellulose of untreated miscanthus forms crystal domains of about $3.0 \mathrm{~nm}$ whereas this size decreases slightly after alkali treatment down to about $2.6 \mathrm{~nm}$. There is no transition to Na-cellulose I during the $\mathrm{NaOH}$ treatment of cellulose (since it would transform after regeneration to Cellulose II crystal structure (Nishimura and Sarko, 1987)) which could explain such decrease. The most probable explanation for this small decrease is that some chains at the surface of crystals were affected by the treatment, decreasing thus its mean size.

The surface morphology of the stem fragments and mineral deposition after silane treatment are illustrated in Fig. 5. The deposition of silica is not uniform and seems to be dependent of tissues and/or of the openness of the structure. Silica was clearly observed in all cases where the silane treatment was applied. Another evident observation of all pictures taken is that a very visible thick layer of silica was observed for the basic treatments, especially B1. EDX analysis confirmed the high abundance of Si during elemental analysis of the mentioned micrograph (Fig. $5 \mathrm{~d}$ ). It is fully in line with the measurements of the rate of $\mathrm{Si}(\mathrm{OH})_{4}$ condensation which was the fastest (Fig. 2) and the measured ash content (silica, Fig. 3). On the contrary, the water and acid samples that presented a low rate of silica condensation in the silicomolybdenum test showed a thinner layer of deposited $\mathrm{SiO}_{2}$ (i.e. W2 in Fig. 5 e and f). No specific differences could be seen by SEM between the mineral deposition on alkali and nonalkali treated stem fragments. 


\subsection{XPS}

$\mathrm{X}$-ray photoelectron spectroscopy was used to compare the elementary composition of untreated miscanthus to the alkali treated counterpart, the silane treated samples in acid (A1) and basic media (B1) and the alkali-treated stem fragments followed by silica coating (A2). These samples were selected in order to i) understand the effect of alkali treatment on miscanthus stem surface (untreated vs alkali treated), ii) visualise any differences on silica deposition with and without previous alkali treatment (A1 vs A2), and iii) to confirm changes on the thickness of the silica deposition when varying $\mathrm{pH}$ (A1 vs B1). The XPS survey spectra for untreated and silica treated B1 (Fig. 6 a) show the common peak attributed to $\mathrm{O} 1 \mathrm{~s}(532.8 \mathrm{eV}), \mathrm{C} 1 \mathrm{~s}(285.5 \mathrm{eV})$ and one peak of $\mathrm{N} 1 \mathrm{~s}$ $(400 \mathrm{eV})$, where carbon and oxygen peaks arise from the carbohydrates of the lignocellulosic stem. The small contribution of nitrogen atoms comes from the plant. The silicon peaks, at $150.0 \mathrm{eV}$ and $103.0 \mathrm{eV}$ for $\mathrm{Si} 2 \mathrm{~s}$ and 2p in $\mathrm{SiO}_{2}$, respectively, were barely observed in the untreated samples but clearly identified in the silane-treated fragments. The slight amount of Si in untreated stem fragments is part of its composition (Brosse et al., 2012). Table 2 summarises the average values for the elemental quantification (\%) of C1s, O1s, Si 2p and N1s, as well as the composition ratio $(\mathrm{O} / \mathrm{C}$ and $\mathrm{Si} / \mathrm{O})$ calculated from the high resolution analysis of the integrated XPS peaks. As an evidence of the successful silica coating, percentage of Si increases after silane treatments of the analysed samples (A1, B1 and A2). The variation of the $\mathrm{O} / \mathrm{C}$ ratio between untreated and alkali-treated samples is due to delignification and removal of hemicelluloses after alkali treatment. The theoretical $\mathrm{O} / \mathrm{C}$ is 0.83 for cellulose and 0.33 for lignin (Matuana et al., 1999). The alkali treatment resulted in the increase of the 
$\mathrm{O} / \mathrm{C}$ ratio from 0.31 (untreated) to 0.38 (alkali treated) due to the removal of unsaturated and aromatic structures during delignification. A similar trend could be expected between $\mathrm{A} 1$ and $\mathrm{A} 2$ samples, but $\mathrm{A} 2$ showed a lower $\mathrm{O} / \mathrm{C}$ ratio than $\mathrm{A} 1$ (Table 2), obviously due to the influence of the silane treatment where the presence of $\mathrm{SiO}_{2}$ contribute to a higher content of $\mathrm{O}$ and therefore a higher $\mathrm{O} / \mathrm{C}$ ratio. The $\mathrm{Si}$ composition between the XPS analysis (Table 2) and the ash content (Fig. 3) are not strictly in agreement. This is attributed to the XPS analysis being limited to a few nanometres in depth and to the analysis of a reduced number of stems, whereas calcination was performed with $1 \mathrm{~g}$ of material. Both analyses agree that A2 stems were less efficiently coated with silica than A1 or B1. On the other hand, the calcination results showed that B1 had the highest percentage of $\mathrm{SiO}_{2}$ and did not differ much from A1. Contrarily, the XPS data evidenced a higher percentage of Si on the fibre surfaces of A1. This suggests that, as observed in the SEM images (Fig. 5), B1 had thicker $\mathrm{SiO}_{2}$ layers but $\mathrm{A} 1$ covered a larger surface area of mineral coating.

\subsection{ATR-FTIR}

The ATR-FTIR spectra of the untreated and by-product of treated miscanthus fragment surfaces are shown in Fig. 7. The broad band in the range between 3600 and $3200 \mathrm{~cm}^{-1}$ corresponds to free $\mathrm{OH}$ and hydration water whereas the sharper peak at $1642 \mathrm{~cm}^{-1}$ is linked to the $\mathrm{HOH}$ bending of adsorbed water (Kačuráková et al., 1998). The alkali treatment resulted in the disappearance of the band at $1730 \mathrm{~cm}^{-1}$, corresponding to carboxyl groups. This is in good agreement with the XPS data (increase in the O/C ratio) as a consequence of the removal of part of the hemicelluloses and lignin components rich in carboxyl groups. In a similar trend, the C-O stretching band at 1250$1240 \mathrm{~cm}^{-1}$ also decreases its intensity to nearly disappearance. This is associated to the alkali hydrogen bonding dissociation between hemicelluloses and cellulose and 
hydrolysis of hemicellulosic ester bonds with their subsequent elimination after rinsing with water (Li et al., 2014; Sun et al., 2000). The small peaks in the range between 1500 and $1400 \mathrm{~cm}^{-1}$ are attributed to $\mathrm{C}-\mathrm{H}, \mathrm{OH}$ or $\mathrm{CH}_{2}$ of lignocellulosic components. The absorption bands in the $1200-940 \mathrm{~cm}^{-1}$ range are difficult to interpret as they correspond to both lignocellulosic material and silica-related compounds. These include the $\mathrm{C}-\mathrm{O}-\mathrm{C}$ vibration $\left(1600 \mathrm{~cm}^{-1}\right), \mathrm{C}-\mathrm{C}, \mathrm{C}-\mathrm{O}$ stretching or C-OH bending $\left(1043 \mathrm{~cm}^{-1}\right)$ and $\mathrm{C}-\mathrm{OH}$ bending for branched structures $\left(1082 \mathrm{~cm}^{-1}\right)$. The same range included bands of Sirelated molecules, such as siloxane bonding ( $\mathrm{Si}-\mathrm{O}-\mathrm{Si})$ and $\mathrm{Si}-\mathrm{O}-\mathrm{C}$. The band at $900 \mathrm{~cm}^{-1}$ is characteristic of $\beta$-glycosilic binding and is present in all samples (Matías et al., 2000). As proven by Matias and co-workers using IR and UV-vis spectroscopy, the reaction between $\mathrm{Si}$-species and hydroxyl groups of the plant fibres depends upon silane structure and heat applied in order to form Si-O-C bonds (Matías et al., 2000). In the present case, since no characteristic chemical group such as amine is present in the silane, the $\mathrm{Si}-\mathrm{O}-\mathrm{C}$ linkage could not be isolated since the $\mathrm{Si}-\mathrm{O}-\mathrm{C}$ band is overlapping with the Si-O-Si peak.

\section{Conclusion}

A sol-gel silane treatment was applied to untreated and alkali pre-treated miscanthus at different media $\mathrm{pH}$, reducing the hydrophilic character of the plant. In all cases, $\mathrm{Si}$ compounds are sitting at the surface whatever was the $\mathrm{pH}$ : acidic, neutral or basic, although at a different yields. This opens the way for studying the influence of the treatment on the adhesion improvement between stem fragments and cement, which will be used later to prepare miscanthus-based concrete. The kinetics of an alkoxysilane precursor hydrolysis and condensation as $\mathrm{Si}-\mathrm{O}-\mathrm{Si}$ were studied by monitoring the amount of $\mathrm{Si}(\mathrm{OH})_{4}$ produced as a function of time. The water absorption capacity of the 
treated plants was taken as an evaluation of their hydrophilic character. The ash content after calcination at $600{ }^{\circ} \mathrm{C}$ gave quantitative information on silica attached to the stem fragments. Electron microscopy observations of the fragment surfaces detailed the morphology of the silica coating. The XPS technique was used as a good indicator of the stem surface elemental composition as well as to provide information on the mechanism of silica deposition. Globally, all these results gave coherent conclusions. Higher and faster silica condensation was achieved at basic conditions as suggested by the $\mathrm{Si}(\mathrm{OH})_{4}$ kinetics, supported by the thick silica layers observed on the samples surface and the higher ash content (related to silica amount). However, elemental quantification by XPS showed a different trend, where the \% $\mathrm{Si}$ was higher in stem fragments treated in acidic conditions. This can be explained by the limitation of the depth of analysis by this technique, being of $10 \mathrm{~nm}$. Therefore, the thick $\mathrm{SiO}_{2}$ layers would not be analysed in its totality and results suggest that the area coated by the silica mineral is higher for the acidic media. The ATR-FTIR and XPS results evidence that the moderate alkali treatment $(5 \% \mathrm{NaOH})$ removes most of components rich in carboxylic groups (i.e. hemicelluloses, lignin) although without significantly affecting cellulose crystallinity as investigated with XRD. Such modifications of miscanthus stem fragments have not been previously reported. The results show that the studied pretreatments can be potentially useful for preparing concrete with better mechanical properties. This is presently under study.

\section{Acknowledgements}


This work was supported by the program Investments for the Future (grant ANR-11BTBR-0006-BFF) managed by the French National Research Agency. We thank Suzanne Jacomet for her help to conduct the SEM analysis.

\section{References}

Belton, D.J., Deschaume, O., Perry, C.C., 2012. An overview of the fundamentals of the chemistry of silica with relevance to biosilicification and technological advances. FEBS J. 279, 1710-20. doi:10.1111/j.1742-4658.2012.08531.x

Bilba, K., Arsene, M.A., 2008. Silane treatment of bagasse fiber for reinforcement of cementitious composites. Compos. Part A Appl. Sci. Manuf. 39, 1488-1495.

doi:10.1016/j.compositesa.2008.05.013

Brosse, N., Dufour, A., Meng, X., Sun, Q., Ragauskas, A., 2012. Miscanthus: a fast-growing crop for biofuels and chemicals production. Biofuels, Bioprod. Biorefining 6, 580-598. doi:10.1002/bbb.1353

Castellano, M., Gandini, A., Fabbri, P., Belgacem, M.N., 2004. Modification of cellulose fibres with organosilanes: Under what conditions does coupling occur? J. Colloid Interface Sci. 273, 505-11. doi:10.1016/j.jcis.2003.09.044

Cuissinat, C., Navard, P., 2006. Swelling and Dissolution of Cellulose Part 1: Free Floating Cotton and Wood Fibres in N-Methylmorpholine-N-oxide-Water Mixtures. Macromol. Symp. 244, 1-18. doi:10.1002/masy.200651201

Iler, R.K., 1979. The Chemistry of Silica, Solubility, Polymerization, Colloid and Surface Properties, and biochemistry. Wiley, New York.

Kačuráková, M., Belton, P.S., Wilson, R.H., Hirsch, J., Ebringerová, A., 1998. Hydration 
properties of xylan-type structures: an FTIR study of xylooligosaccharides. J. Sci. Food Agric. 77, 38-44. doi:10.1002/(SICI)1097-0010(199805)77:1<38::AID-JSFA999>3.0.CO;2-5

Li, M., Si, S., Hao, B., Zha, Y., Wan, C., Hong, S., Kang, Y., Jia, J., Zhang, J., Li, M., Zhao, C., Tu, Y., Zhou, S., Peng, L., 2014. Mild alkali-pretreatment effectively extracts guaiacyl-rich lignin for high lignocellulose digestibility coupled with largely diminishing yeast fermentation inhibitors in Miscanthus. Bioresour. Technol. 169, 447-454. doi:10.1016/j.biortech.2014.07.017

Matías, M.C., De La Orden, M.U., Sánchez, C.G., Urreaga, J.M., 2000. Comparative spectroscopic study of the modification of cellulosic materials with different coupling agents. J. Appl. Polym. Sci. 75, 256-266. doi:10.1002/(SICI)1097-4628(20000110)75:2<256::AIDAPP8>3.3.CO;2-Q

Matuana, L.M., Balatinecz, J.J., Park, C.B., Sodhi, R.N.S., 1999. X-ray photoelectron spectroscopy study of silane-treated newsprint-fibers. Wood Sci. Technol. 33, 259-270. doi:10.1007/s002260050114.

Mehta, P.K., Monteiro, P.J.M., 2006. Concrete: microstructure, properties, and materials. McGraw-Hill, New York.

Mwaikambo, L.Y., Ansell, M.P., 2002. Chemical modification of hemp, sisal, jute, and kapok fibers by alkalization. J. Appl. Polym. Sci. 84, 2222-2234. doi:10.1002/app.10460

Nishimura, H., Sarko, A., 1987. Mercerization of cellulose. III. Changes in crystallite sizes. J. Appl. Polym. Sci. 33, 855-866. doi:10.1002/app.1987.070330314

Pehanich, J.L., Blankenhorn, P.R., Silsbee, M.R., 2004. Wood fiber surface treatment level effects on selected mechanical properties of wood fiber-cement composites. Cem. Concr. Res. 34, 59-65. doi:10.1016/S0008-8846(03)00193-5

Pude, R., Treseler, C.H., Trettin, R., Noga, G., 2005. Suitability of Miscanthus genotypes for 
lightweight concrete. Bodenkultur 56, 61-69.

Reddy, K.O., Maheswari, C.U., Reddy, D.J.P., Rajulu, A.V., 2009. Thermal properties of Napier grass fibers. Materials Letters 63, 2390-2392. doi:10.1016/j.matlet.2009.08.035

Scherrer, P., 1912. Kolloidchemie Ein Lehrbuch. Springer Berlin Heidelberg, Berlin, Heidelberg, pp. 387-409. doi:10.1007/978-3-662-33915-2_7

Sun, R.C., Tomkinson, J., Ma, P.L., Liang, S.F., 2000. Comparative study of hemicelluloses from rice straw by alkali and hydrogen peroxide treatments. Carbohydr. Polym. 42, 111-122. doi:10.1016/S0144-8617(99)00136-8

Thakur, V.K., Singha, A.S., 2010. Mechanical and Water Absorption Properties of Natural Fibers/Polymer Biocomposites. Polym. Plast. Technol. Eng. 49, 694-700.

doi:10.1080/03602551003682067

Valadez-Gonzalez, A., Cervantes-Uc, J.M., Olayo, R., Herrera-Franco, P.J., 1999. Effect of fiber surface treatment on the fiber-matrix bond strength of natural fiber reinforced composites. Compos. Part B Eng. 30, 309-320.

Vo, L., Navard, P., 2016. Treatments of plant biomass for cementitious building materials - A review. Submitted to Constr. Build. Mater.

Xie, Y., Hill, C.A.S., Xiao, Z., Militz, H., Mai, C., 2010. Silane coupling agents used for natural fiber/polymer composites: A review. Compos. Part A Appl. Sci. Manuf. 41, 806-819. doi:10.1016/j.compositesa.2010.03.005 


\section{Caption for Figures and Tables}

Fig.1. Size distribution in percentage of frequency of initial miscanthus a) length and b) width.

Fig. 2. Evolution of available $\mathrm{Si}(\mathrm{OH})_{4}$ without miscanthus stem fragments (blank) and in the presence of miscanthus stem fragments in a) water ( $\mathrm{pH} \sim 6), \mathrm{b})$ acidic $(\mathrm{pH} 4)$ and c) basic media ( $\mathrm{pH} 10)$.

Fig. 3. Weight percentage for water absorption (black) and ash content (grey) of untreated and treated miscanthus.

Fig. 4. Left: Electron microscopy micrographs of a) untreated and b) alkali-treated miscanthus surface and c) untreated and d) alkali treated+ silane coated miscanthus (B2) with z-axes view. Right: XRD spectrum of untreated and alkali treated miscanthus.

Fig. 5. Micrographs of stem fragments after silane treatment of W1 (a), A1 (b), B1 (c), W2 (e), A2 (g) and B2 (h). Graphs in (d) and (f) are the EDS analysis of the selected regions of the micrographs in (c) and (e), respectively.

Fig. 6. X-ray photoelectron spectroscopy diagrams of untreated and silica coated miscanthus (B1).

Fig. 7. Absorbance versus wavenumber as measured by ATR-FTIR for the eight different samples.

Table 1. Nomenclature of the treatments applied to the miscanthus stem fragments.

Table 2. Average values of elemental composition (\%) and composition ratio of $\mathrm{O} / \mathrm{C}$ and $\mathrm{Si} / \mathrm{O}$ from XPS integration analysis. 
Table 1. Nomenclature of the treatments applied to the miscanthus stem fragments.

\begin{tabular}{lll}
\hline Sample name & Media silane treatment & Alkali pre-treated \\
\hline Untreated & No silane & NO \\
W1 & Aqueous $(\mathrm{pH} 6)$ & NO \\
A1 & Acid $(\mathrm{pH} 4)$ & NO \\
B1 & Basic $(\mathrm{pH} \mathrm{10)}$ & NO \\
Alkali treated & No silane & YES \\
W2 & Aqueous $(\mathrm{pH} 6)$ & YES \\
A2 & Acid $(\mathrm{pH} \mathrm{4)}$ & YES \\
B2 & Basic $(\mathrm{pH} \mathrm{10)}$ & YES \\
\hline
\end{tabular}

Table 2. Average values of elemental composition (\%) and composition ratio of $\mathrm{O} / \mathrm{C}$ and $\mathrm{Si} / \mathrm{O}$ from XPS integration analysis.

\begin{tabular}{lllllll} 
& \multicolumn{3}{l}{$\begin{array}{l}\text { Elemental } \\
\text { composition (\%) }\end{array}$} & \multicolumn{3}{c}{ Ratio } \\
\cline { 2 - 7 } & $\mathbf{C}$ & $\mathbf{O}$ & $\mathbf{S i}$ & $\mathbf{N}$ & $\mathbf{O} / \mathbf{C}$ & $\mathbf{S i} / \mathbf{O}$ \\
\hline Untreated & 75.7 & 23.1 & 0.2 & 1.1 & 0.31 & 0.01 \\
A1 & 59.4 & 34.1 & 5.3 & 1.2 & 0.58 & 0.15 \\
B1 & 65.9 & 30.1 & 2.7 & 1.4 & 0.46 & 0.08 \\
Alkali & 72.5 & 26.7 & 0.1 & 0.7 & 0.37 & 0.00 \\
A2 & 69.4 & 28.9 & 1.0 & 0.7 & 0.42 & 0.03 \\
\hline
\end{tabular}



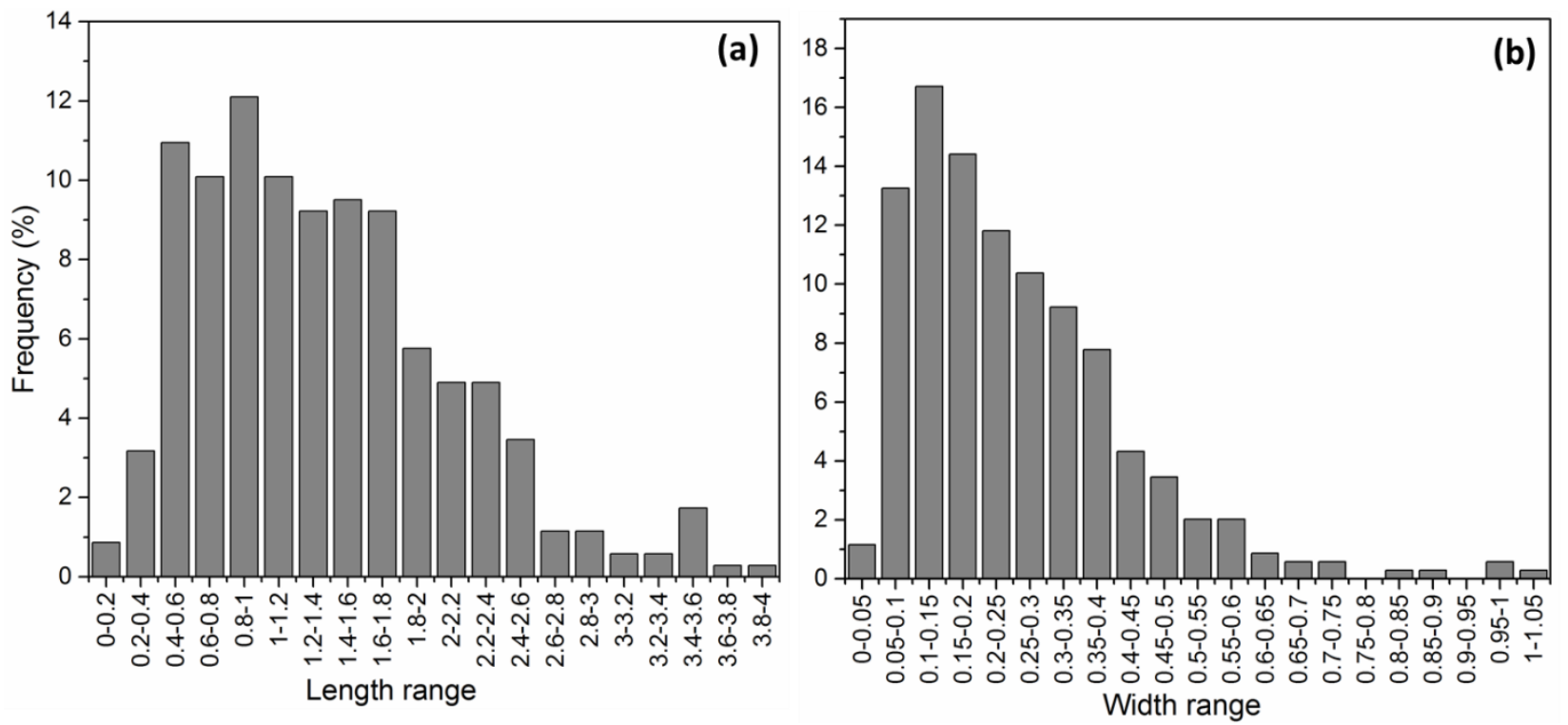

Fig.1. Size distribution in percentage of frequency of initial miscanthus a) length and b) width.
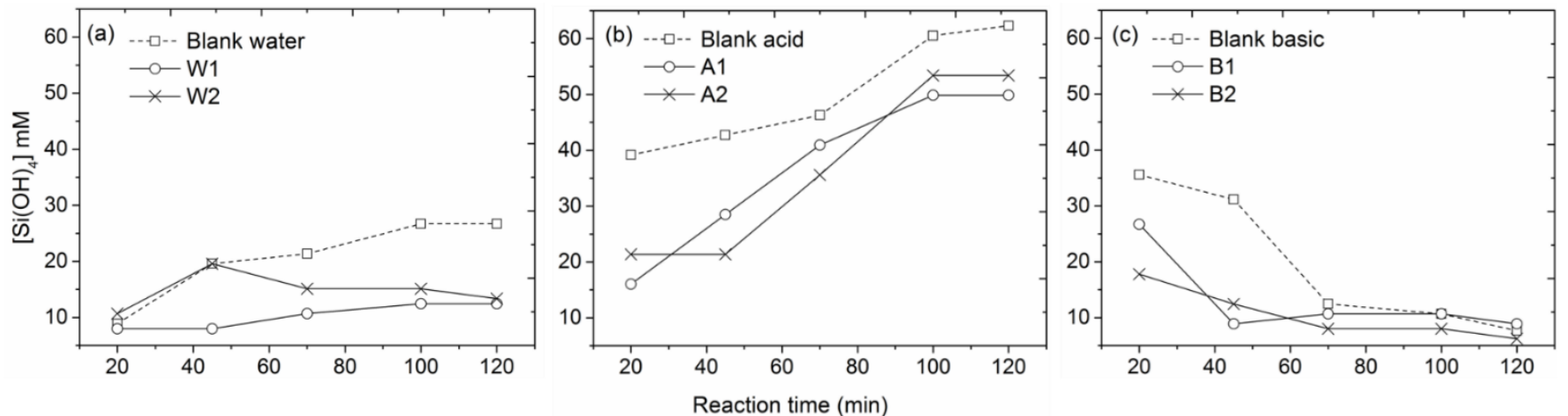

Fig. 2. Evolution of available $\mathrm{Si}(\mathrm{OH})_{4}$ without miscanthus stem fragments (blank) and in the presence of miscanthus stem fragments in a) water ( $\mathrm{pH} \sim 6)$, b) acidic ( $\mathrm{pH} 4)$ and c) basic media ( $\mathrm{pH} 10)$. 


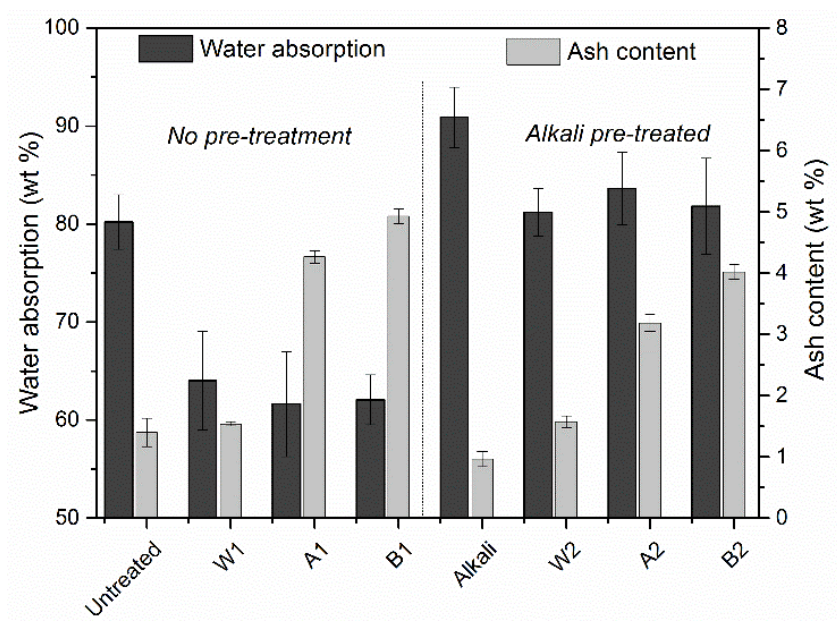

Fig. 3. Weight percentage for water absorption (black) and ash content (grey) of untreated and treated miscanthus.
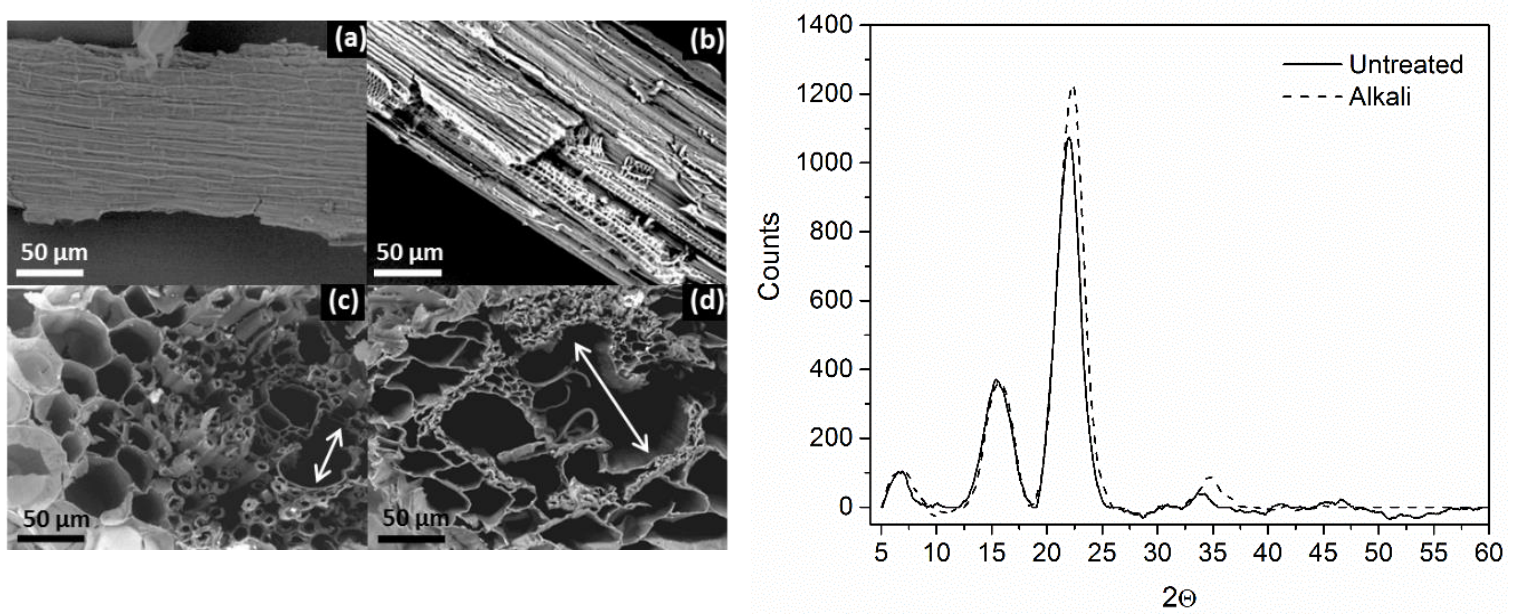

Fig. 4. Left: Electron microscopy micrographs of a) untreated and b) alkali-treated miscanthus surface and c) untreated and d) alkali treated+ silane coated miscanthus (B2) with z-axes view. Right: XRD spectrum of untreated and alkali treated miscanthus. 


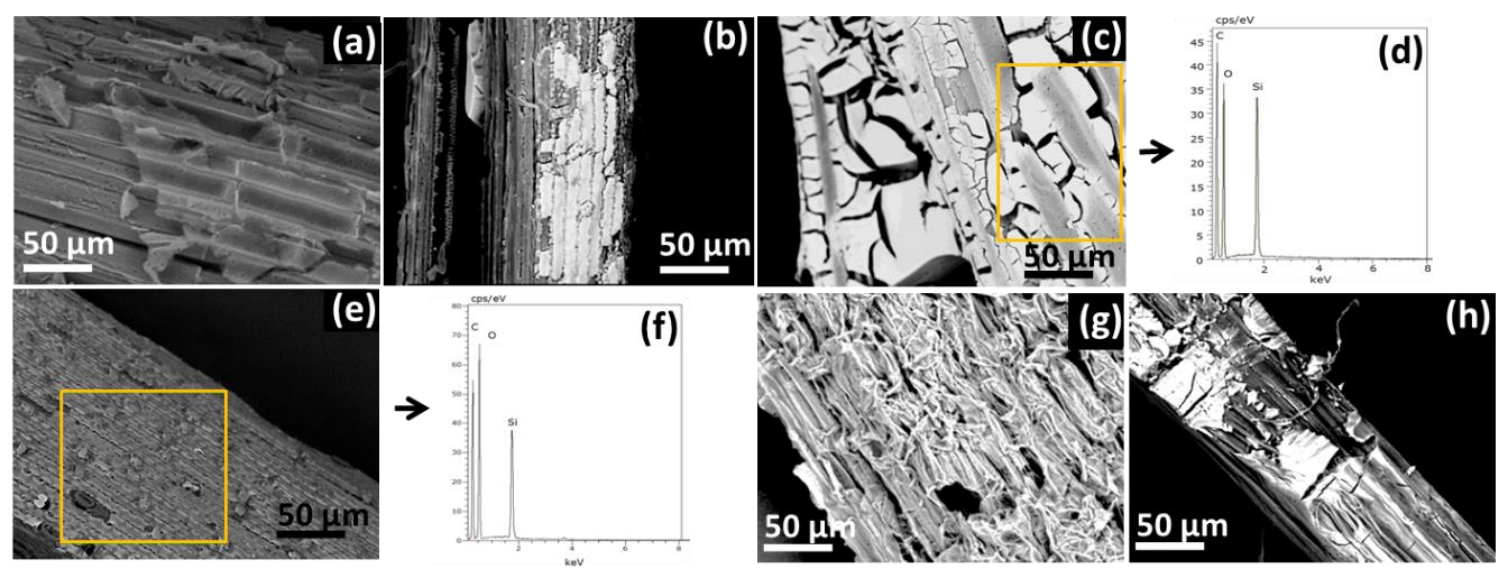

Fig. 5. Micrographs of stem fragments after silane treatment of W1 (a), A1 (b), B1 (c), W2 (e), A2 (g) and B2 (h). Graphs in (d) and (f) are the EDS analysis of the selected regions of the micrographs in (c) and (e), respectively.

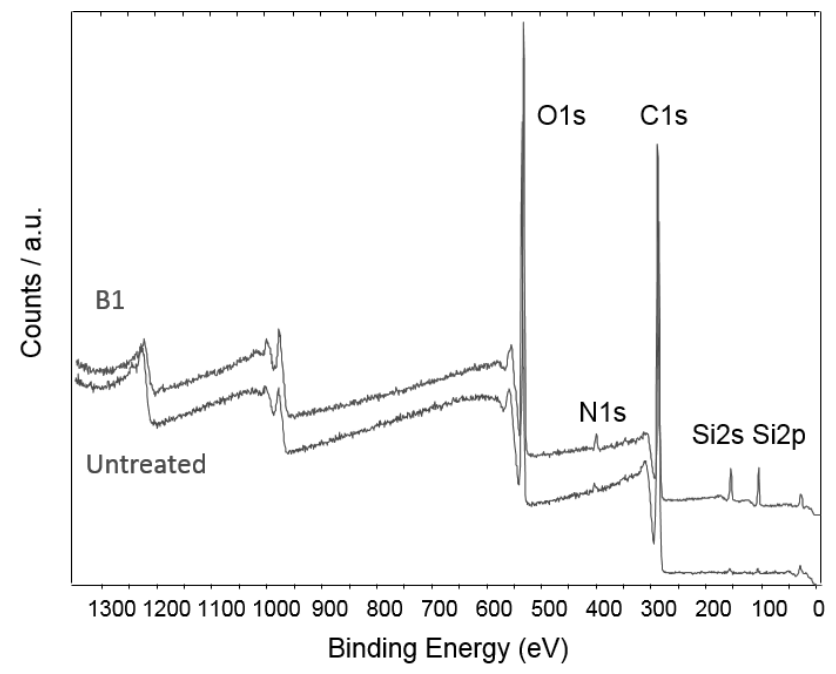

Fig. 6. X-ray photoelectron spectroscopy diagrams of untreated and silica coated miscanthus (B1). 


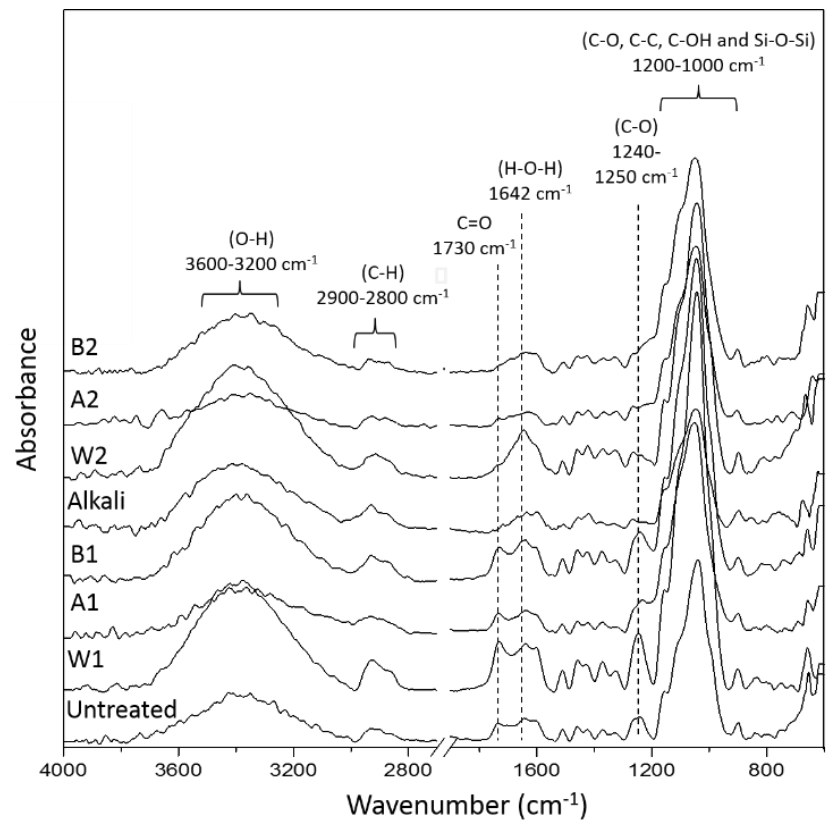

Fig. 7. Absorbance versus wavenumber as measured by ATR-FTIR for the eight different samples. 